\title{
Characterization of a wind turbine wake evolving over an intertidal zone performed with dual-lidar observations
} Changzhong Feng ${ }^{1}$, Bingyi Liu ${ }^{1}$, Songhua $\mathrm{Wu}^{1,2}$, Jintao Liu ${ }^{1}$,Rongzhong $\mathrm{Li}^{3}$, Xitao Wang ${ }^{3}$

${ }^{1}$ Ocean Remote Sensing Institute, Ocean University of China, Qingdao 266100, China

5 Laboratory for Regional Oceanography and Numerical Modeling, Qingdao National Laboratory for Marine Science and Technology

${ }^{3}$ Seaglet Environmental Technology, Qingdao, China

Correspondence to: (liubingyi@ouc.edu.cn)

Abstract. As modern wind power industry quickly develops, it is of high priority to optimize layouts and operations of wind turbines to reduce the influences of wakes induced by upstream wind turbines. The wake behaves complicatedly with landocean-atmosphere interactions. This complex wake could be observed by two or more synchronously operated Doppler lidars. Accordingly, we characterized a wind turbine wake evolving over an intertidal zone performed with dual-lidar observations. Dynamic process of wakes merging that occurred from approximately $1 \mathrm{D}$ (rotor diameter) downstream was captured and analysed. The phenomenon that wake length increased with rising tide was analysed in details. It suggested that

15 the increase of wake length varied with underlying surface roughness transition from mud to sea water as well as the rising sea level. Finally, wake meandering cases were analyzed in detail. Our research shows that the dual-lidar observation technology is a promising remote sensing tool for characterization of complicated wind turbine wakes.

\section{Introduction}

Wind energy is no doubt one of the most promising alternative energies. As wind power industry increases rapidly during the past decades, optimizations of wind turbines layouts and operations have presented a significant challenge to minimize the cost of energy. Specifically, considerably decreased output power and enhanced fatigue are induced by upstream turbine wakes (Baker and Walker, 1984; Barthelmie et al., 2003; Chowdhury et al., 2012). Therefore, various experiments and simulations have been performed previously in an attempt to investigate the dependence of the wake behaviours (velocity deficit, wake length, wake boundary and wake centreline) on the atmospheric conditions (wind speed, turbulence, surface roughness and atmospheric stability). Full-scale experiment could convincingly help the validation of large-eddy simulation (LES) technique combined with turbine model (Abkar and Porté-Agel, 2015; Iungo et al., 2013; Porté-Agel et al., 2011; Wu and Porté-Agel, 2012), and ultimately improve the prediction of wind power harvesting (Aitken and Lundquist, 2014; Fuertes et al., 2014; Hirth et al., 2012).

The conventional approach to obtain wind data at a fixed point is to utilize cup anemometers mounted on meteorological towers (Baker and Walker, 1984; Elliott and Barnard, 1990). However, the investigation of complex wake structure needs 
Atmos. Meas. Tech. Discuss., doi:10.5194/amt-2017-23, 2017

Manuscript under review for journal Atmos. Meas. Tech.

Discussion started: 31 March 2017

(c) Author(s) 2017. CC-BY 3.0 License.
Atmospheric

Measurement

Techniques

Discussions

more data points. For instance, Elliott et al. analysed wake characteristics from wind data of nine meteorological towers (Elliott and Barnard, 1990). Nevertheless, the impact of towers with large cross-sections on the measurements at hub height should be taken into consideration. Therefore, the remote sensing technique such as lidar, radar, and sodar has been increasingly adopted in experimental turbine wake research. Högström et al. utilized four different equipments, including a

5 kite anemometer, a tower-mounted instrumentation, a tethered balloon sounding and a Sonic Detection and Ranging (SODAR), to obtain the vertical profile of turbulence intensity (Högström et al., 1988). Kambezidis et al. employed three SODARs placed at equal distances downstream of a turbine to investigate velocity deficit, turbulence intensity and temperature structure within the wake (Kambezidis et al., 1990). In situ measurement combine with acoustic sounders was used to identify rotational motion inside the wake by Helmis et al.(Helmis et al., 1995). Barthelmie et al. elaborately

10 evaluated the operation of the SODAR mounted on a ship for measuring offshore wind turbine wake, and quantified the relationship between wind farm efficiency and various atmospheric conditions (Barthelmie et al., 2003; Barthelmie and Jensen, 2010).

For a pulsed coherent Doppler lidar (PCDL), access to the full-scale wind turbine wake could be provided by a variety of geometrical scanning modes (Bingöl et al., 2010; Käsler et al., 2010; Trujillo et al., 2011; Wu et al., 2016; Wu et al., 2014).

15 The lidar deployment and wind direction should be taken into account because lidar directly obtains Light of Sight (LOS) velocity. For instance, the lidar-turbine line should be strictly aligned with the turbine wake in the RHI (Range Height Indicator) mode (Kopp et al., 2004; Smalikho et al., 2005), which sweeps elevation angle with a fixed azimuth angle (Käsler et al., 2010). However, this scanning mode could not always intersect the wake particularly at far wake region due to wake meandering and the variation of wind direction and turbine yaw. Similarly, when lidar operates by sweeping azimuth angle

20 with the constant elevation angle, called Plane Position Indicator (PPI) mode, the distance and orientation from lidar to turbine should be sufficiently far and roughly same with wind direction (Smalikho et al., 2013), respectively. In general, detected wake length is limited by the increasing altitude with range and wake orientation for both PPI and RHI mode of PCDL. Furthermore, analysis of these measurements is based on LOS velocity or simple projection along wake orientation.

Vector wind field could be retrieved based on two or more independent measurements (Armijo, 1969; Ray et al., 1978;

25 Rothermel et al., 1985). Three pulsed coherent lidars of Leosphere were employed to deduce the measurements at a fixed point, which was compared with the data collocated from sonic anemometer by Mann et al. (Mann et al., 2009). To investigate axial and vertical velocity components, simultaneous measurements utilizing two lidars with RHI mode were performed behind a wind turbine by Iungo et al. (Iungo et al., 2013). For this case, one lidar was placed at the turbine location and the other one was located downstream. Hirth et al. employed two radars to reconstract wake structure, and then

30 discussed the variability of a single turbine wake and the complex flow features included in a wind farm (Hirth and Schroeder, 2013; Hirth et al., 2015).

\subsection{Velocity deficit and wake length}

Definition of velocity deficit at hub height in previous studies can be written as: 
Atmos. Meas. Tech. Discuss., doi:10.5194/amt-2017-23, 2017

Manuscript under review for journal Atmos. Meas. Tech.

Discussion started: 31 March 2017

(c) Author(s) 2017. CC-BY 3.0 License.

\section{Atmospheric \\ Measurement \\ Techniques \\ Discussions}

$\delta(x)=\frac{U_{r e f}(x)-U_{w a k e}(x)}{U_{r e f}(x)} \times 100 \%$,

where, $U_{r e f}(x)$ is the ambient or reference velocity as a function of longitudinal distance $x$ downstream from the wind turbine, $U_{\text {wake }}(x)$ is the wake velocity. The initial value depends on the amount of momentum loss induced by wind turbine (Wu et al., 2016), with typical value of approximately 50\%-60\% (Aitken et al., 2014), 66\% in (Kambezidis et al., 1990) and

$574 \%$ in (Smalikho et al., 2013). Wake length $L$ is the distance, at which the velocity deficit drops down to 10\% (Smalikho et al., 2013), with typical value of 7-10 rotor diameters (D) and extreme value of exceeding 20 D (Hirth and Schroeder, 2013) and $30 \mathrm{D}$ (Hirth et al., 2012).

The environmental factors that affect velocity and wake length include wind speed, turbulence, atmospheric stability and surface roughness. Researches indicate that velocity deficit is notably higher at lower ambient velocity owing to higher thrust coefficients (Elliott and Barnard, 1990). It shows that the lowest turbulence intensity occurs at $8-12 \mathrm{~ms}^{-1}$, in which case the velocity deficit is high due to high turbine thrust coefficient (Elliott and Barnard, 1990; Hansen et al., 2012). Besides, turbulence plays an important role in mixing effect between wake and surrounding air (Aitken et al., 2014), and strongly affects velocity deficit in the far wake (Rhodes and Lundquist, 2013). For instance, Smalikho et al. proposed that wake length would be half when the turbulent energy dissipation rate doubles at high wind speed (Smalikho et al., 2013). In

15 addition, unstable atmospheric conditions would result in the enhancement of turbulence intensity levels. Such as, wind turbine wake recovers faster in convective condition than in neutral condition (Iungo, 2016). However, the factor of surface roughness on wind farm needs more elaborate investigations.

\subsection{Wake centreline and width}

As pointed out by Vermeer et al., downstream wake could be separated into two parts: near and far wake regions, with the

20 dividing line a few $\mathrm{D}$ downwind of the corresponding wind turbine (Vermeer et al., 2003). In the near wake region, the velocity behind the turbine rotor decreases owing to the lift generated along the blade, with a maximum lift value near 75\% blade span. Consequently, wind profile of horizontal cross section in the near wake region has two peaks (Smedman, 1998), or double-bell shape (Aitken et al., 2014; Larsen et al., 2007),

$U(y, r)=U_{r e f}-a_{1} \times\left\{\exp \left[-\left(\frac{y-y_{1}}{c_{1}}\right)^{2}\right]+\exp \left[-\left(\frac{y-y_{2}}{c_{1}}\right)^{2}\right]\right\}$

25 As distance increases downwind, tip vortexes with spirals pattern gradually entwine into one with cross section wind profile of single centreline peak or Gaussian-like shape (Aitken et al., 2014; Larsen et al., 2007),

$U(y, r)=U_{r e f}-a_{0} \times \exp \left[-\left(\frac{y-y_{0}}{c_{0}}\right)^{2}\right]$.

In Eq.(2) and Eq.(3) $U_{r e f}$ is the ambient wind speed, $a_{1}$ and $a_{0}$ are the amplitudes of the Gaussian curve, $C_{1}$ and $C_{0}$ are the parameters to describe the wake width, $y_{1}, y_{2}$ and $y_{0}$ are the locations of the left, right and center minima in the double- 
Atmos. Meas. Tech. Discuss., doi:10.5194/amt-2017-23, 2017

Manuscript under review for journal Atmos. Meas. Tech.

Discussion started: 31 March 2017

(c) Author(s) 2017. CC-BY 3.0 License.
Atmospheric

Measurement

Techniques

Discussions

Gaussian and single-Gaussian curves, respectively. As defined in (Aitken et al., 2014; Hansen et al., 2012), wake width of single-Gaussian shape, with definition of $95 \%$ confidence interval of velocity profile, can be written as:

$w_{1}=2 \sqrt{2} C_{0}$,

while, width of wake with double-Gaussian distribution can be expressed as:

$5 \quad w_{2}=2 \sqrt{2} C_{1}+\left|y_{1}-y_{2}\right|$,

As wake propagates downstream, wake width and centreline behave as in what follows. Due to the mixing effect by smallscale atmospheric eddies (Bingöl et al., 2010), wake expands larger with incremental distance downwind in the horizontal direction than in vertical direction owing to ground effect (Aitken et al., 2014). In addition to wake width, wake centreline shifts upward in the vertical direction due to the larger momentum at the lower part of the wake than in the higher part of the

10 wake (Helmis et al., 1995) and the tilt of the rotor (Aitken et al., 2014). Besides, horizontal displacements of wake centreline are larger than vertical displacements with the ratio of approximately 1.5 (España et al., 2011).

This paper presents characterization of intertidal turbine wakes based on the two pulsed coherent Doppler lidars. In what follows, section 2 subsequently describes the dual-Doppler experimental setup. In section 3, observation results, including wakes merging, wake evolution with rising tide and wake meandering, are presented and analysed. Finally, summary and

15 discussion are offered in section 4.

\section{Description of the experiment}

A dual-lidar experiment for measuring wind turbine wakes was performed on December 15, 2014, with cloudy weather condition and westerly to northwesterly wind at the Jiangsu Rudong intertidal wind farm ( $32^{\circ} 31^{\prime} 17^{\prime \prime} \mathrm{N}, 121^{\circ} 10^{\prime} 32^{\prime \prime}$ E). Two lidars were deployed on the embankment with the intertidal zone at the top right of the lidar-lidar line and the coast at the

20 bottom of Fig. 1. The tilted plane scanning mode was adopted for turbine wakes observation with elevation denoted by the gray contour lines in Fig. 1. The 2-MW wind turbine T1 had a 100-m rotor diamter and a hub height of 80m. The hub height and rotor diamer of the 1.5-MW wind turbine T5, T6 and T7 were $80 \mathrm{~m}$ and $93 \mathrm{~m}$, respectively. Two gasoline engine generators were deployed for power supply. Sea Surface Temperature (SST) from European Centre For Medium Range Weather Forecasts (ECMWF) showed that the sea surface temperature was appximatly $10^{\circ}$ which was at least $4^{\circ}$ higher than 25 the air temperature $\left(-1^{\circ}-6^{\circ}\right.$ at local weather station http://lishi.tianqi.com/rudong/201412.html). To obtain the rough time when tide began to rise and reached highest point, the tidal level data was achieved from the nearest Yangkou Harbour (http://www.chinaports.com/chaoxi), located southeast with a distance of approximately $18 \mathrm{~km}$. Data from the harbour showed that tide began to rise after 1204 local time (LT) with tide height of $222 \mathrm{~cm}$ and reached the maximum value of 398 $\mathrm{cm}$ at $1811 \mathrm{LT}$. Accordingly, the tide at the experiment was supposed to be rising from 1300LT to 1700LT. 


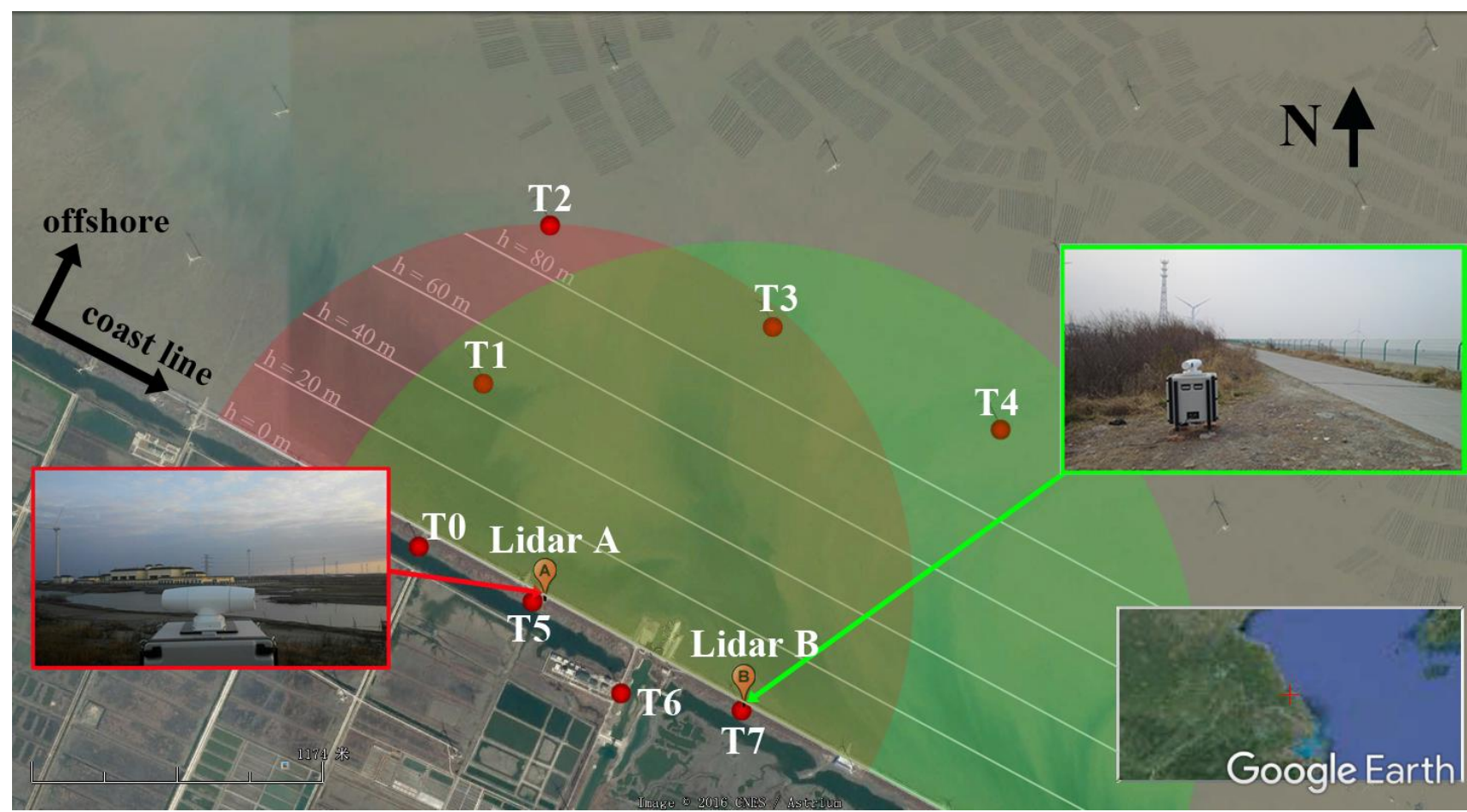

Figure 1: Map of the experiment at an intertidal wind farm of Rudong in Jiangsu province of China with the position of wind turbines (denoted by red dots), two scanning lidar (denoted by balloon A and B), the measurement area (denoted by red and green shadows). The gray lines are contours of the tilted measurement plane.

5 Two pulsed coherent Doppler lidars (WindPrint S4000) operated are from Seaglet Environmental Technology and modified by Ocean University of China (OUC), with AHRS (Attitude and Heading Reference System) and GPS (Global Position System) modules to record attitude and position information. Laser pulse width was tuned to $100 \mathrm{~ns}$, corresponding to spatial resolution of $15 \mathrm{~m}$ in the radial direction. This system has pulse repetition rates of $10 \mathrm{kHz}$ and scanning speed of up to $55 \%$, which enables LOS velocity to be measured with temporal resolution of up to $0.25 \mathrm{~s}$. Besides, access to high spatial

10 resolution of up to $15 \mathrm{~m}$ during scanning measurements could be provided by the tunable pulse width of 100-400 ns and beam pointing accuracy of $0.1^{\circ}$. The component parameters of two systems are given in (Wu et al., 2016). The effective operating range of both lidars were approximately $1.5 \mathrm{~km}$ and $2 \mathrm{~km}$, respectively, owing to different optical efficiency between two lidars, which are denoted by shadows as shown in Fig. 1. The contribution of vertical wind component to the measured LOS velocity could be neglected due to the small elevation of laser beams. Wind vector at a certain point could be 15 precisely retrieved from two non-collinear LOS velocities. Therefore, two-dimension vector winds can be obtained by applying this method to the overlap of two scanning ranges.

To achieve vector wind measurements in a certain titled plane, a new scanning mode was used by adjusting the reference planes of two instruments to a tilted plane according to specified requirement. So that a coplanar scanning measurement can be simply achieved by using two instruments to perform synchronous PPI scans with zero elevation in their reference plane. 
Atmos. Meas. Tech. Discuss., doi:10.5194/amt-2017-23, 2017

Manuscript under review for journal Atmos. Meas. Tech.

Discussion started: 31 March 2017

(c) Author(s) 2017. CC-BY 3.0 License.

(c) (i)

Atmospheric

Measurement

Techniques

Discussions

Detailed methdology of this scanning mode is described in a separated paper being prepared. The angle of both tilted planes was tuned to $4^{\circ}$, adapted to various wind directions and the requirement of obtaining as many wake measurements as possible. In this case, altitude of the tilted plane at wind turbine $\mathrm{T} 1$ was about $45 \mathrm{~m}$ in the low part of wake (wind turbine rotor disk spans a height of 30-130 m). That was favorable to observe the wake in the far wake region because wake decays

5 much more rapidly above the hub height than below the corresponding owing to ground effect (Aitken et al., 2014; Elliott and Barnard, 1990). Each scanning took approximately $90 \mathrm{~s}$ as the azimuth ranges of two systems were set to $180^{\circ}$ with the angular velocity of $2{ }^{\circ} \mathrm{s}^{-1}$ programmed in a script in advance. In practice, the azimuth range could be reduce to $120^{\circ}$, which further reduced the period of each scanning. The effective measurement time ranged from 1020 LT to 1638 LT, which enabled approximately 220 data sets to be collected. Results contaminated by upwind turbines and severe fluctuation of 10 ambient wind field were screened out and the rest were analysed in what follows.

\section{Results}

\subsection{Wake merging}

Four consecutive retrieved 2D wind fields are shown in Fig. 2, in which wind speeds are indicated by colors with spatial resolution of $15 \mathrm{~m}$ and the directions are denoted by black arrows with spatial resolution of $45 \mathrm{~m}$. The eliminated values at the

15 distance of about $0.5 \mathrm{~km}$ around lidar B was caused by the data quality control. The contour gray lines indicate the elevation of the titlted plane. Titles of four panels specify the operating time of two lidars. As can be seen in Fig. 2(a), wind blowed from southwest and two wakes apeared as cooler colours were produced in the downstream of wind turbine T4 and T5. The minimum height of two wakes observed in titled plane was about $15 \mathrm{~m}$, but the rotor sweep region was 33.5-126.5 m. That could be explaned by the wake expanding in vertical direction (Aitken et al., 2014). In Fig. 2(b) to (d), both two wakes

20 gradually merged together with lateral displacement and resulted in the difficulty to distinguish, which were analyzed in what follows.

To quantify spatial variation of the wakes downstream of wind turbine T4 and T5, the vertical transects across the wakes downstream are shown in Fig. 2 and denoted by the red rectangles. From the transects, variation of retrieved wind speed clearly showed a double wake generated by the two wind turbines denoted by T4 and T5 in Fig. 3(a), which also showed that

25 the turbine wake had a limited lateral expansion. The lowest wind speed with value of $3.2 \mathrm{~ms}^{-1}$ appeared downstream of turbine T5. Besides, the maximum wind speed in lateral of each wake was comparable with that at the upstream (Li and Lehner, 2013). For instance, the maximum wind speed in lateral of the wakes was $7.8 \mathrm{~ms}^{-1}$ and could be treated as the ambient wind speed. In this case, the corresponding maximum velocity deficit was about 59\%. The two separate wakes started to merge as shown in Fig. 3(b)(c) and only one wake was visible in the transect shown in Fig. 3(d). In contrast to the

30 result from Li and Lehner based on X-band TerraSAR data, in which the merging processes are exhibited by comparing two transects at different distance downstream of wind turbines (Li and Lehner, 2013), this case showed the variation of merging process with time at a fixed transect. 
Atmos. Meas. Tech. Discuss., doi:10.5194/amt-2017-23, 2017

Manuscript under review for journal Atmos. Meas. Tech.

Discussion started: 31 March 2017

(c) Author(s) 2017. CC-BY 3.0 License.
Atmospheric

Measurement

Techniques

Discussions

\section{(c) (1)}

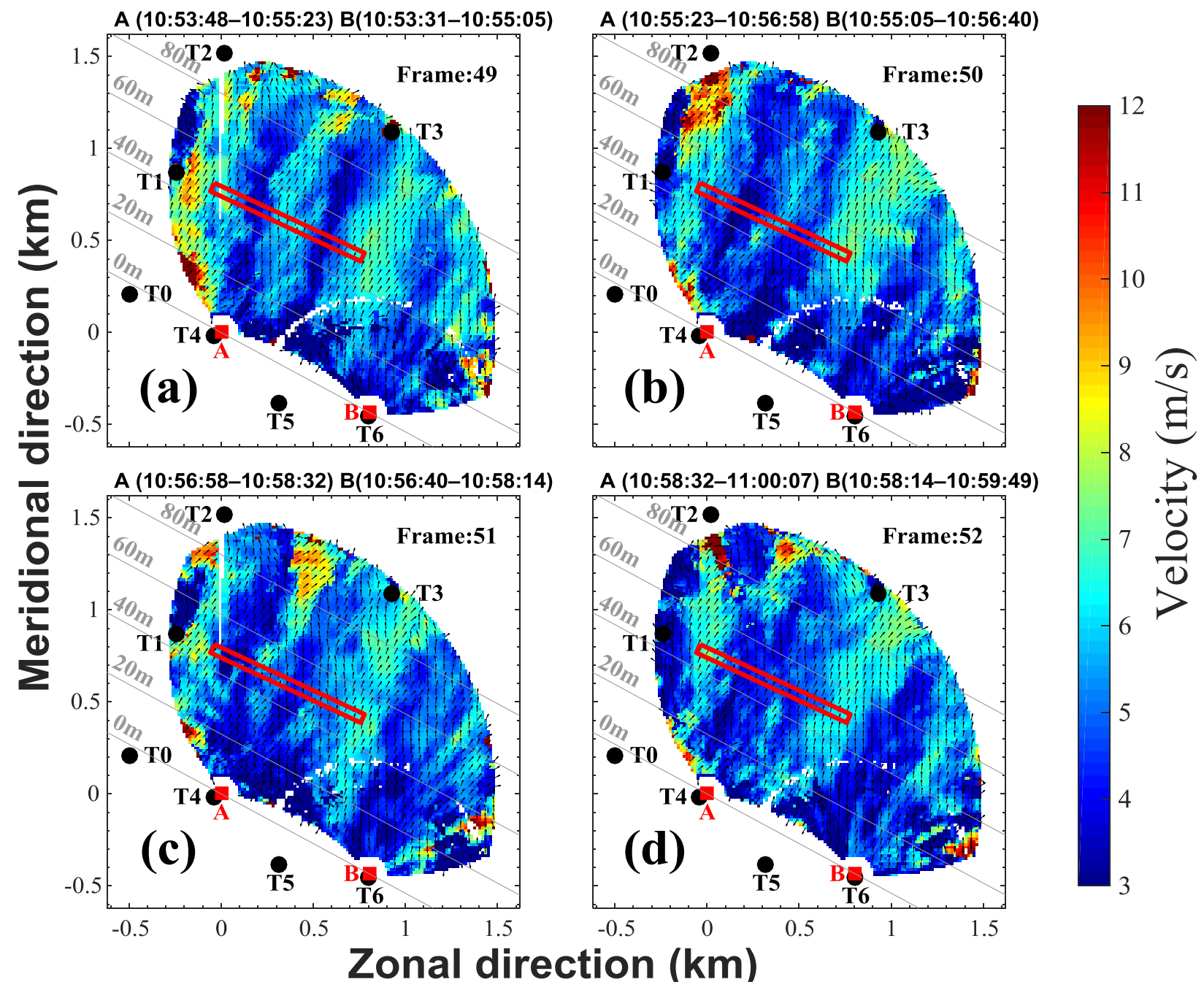

Figure 2: Four consecutive wind fields retrieved based on two lidars (indicated by red solid rectangles). The spatial resolution of wind speed was $15 \mathrm{~m}$ and wind direction (denoted by black arrows) was $45 \mathrm{~m}$. Velocities in red solid rectangles are used to quantify spatial variation of wakes at the distance of about $1 \mathrm{~km}$ downstream of wind turbine T5 and T6. 
Atmos. Meas. Tech. Discuss., doi:10.5194/amt-2017-23, 2017

Manuscript under review for journal Atmos. Meas. Tech.

Discussion started: 31 March 2017

(c) Author(s) 2017. CC-BY 3.0 License.

(c) (i)
Atmospheric

Measurement

Techniques

Discussions

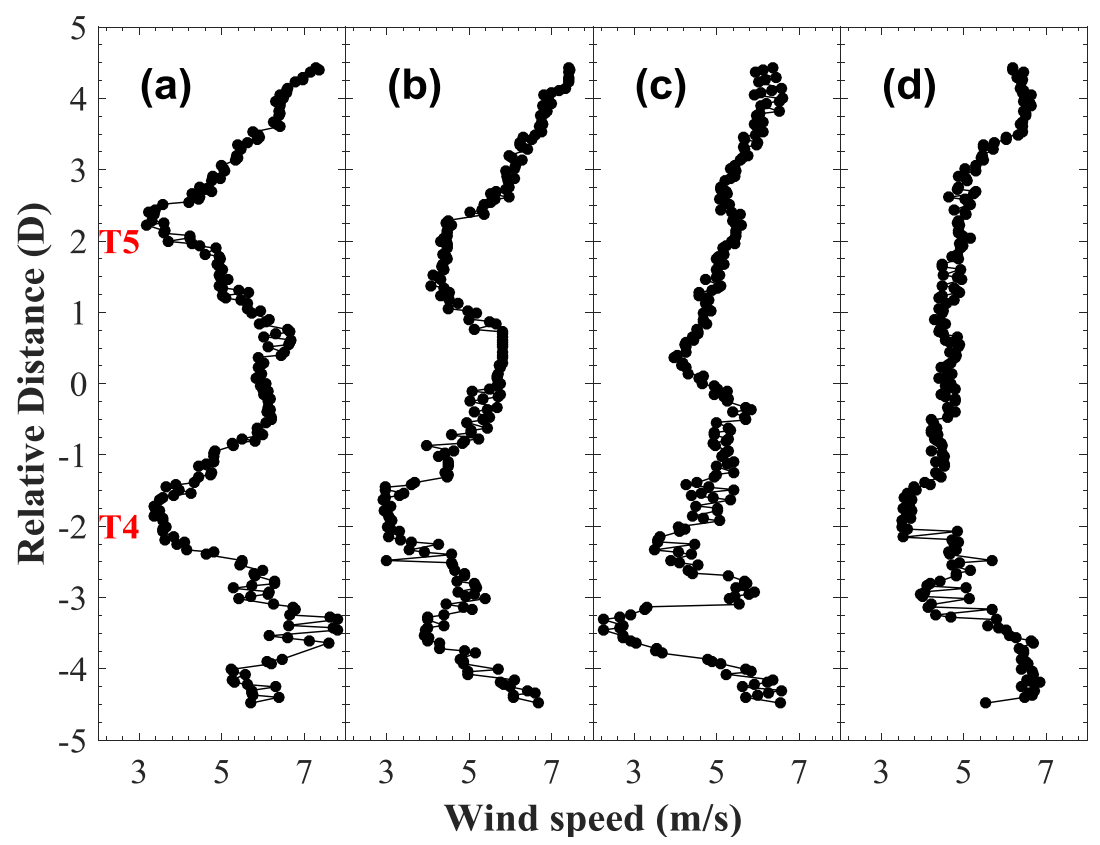

Figure 3: Variation of the wind speed in the transects across the wakes at distance of approximately 1D downstream of wind turbine T4.

\subsection{Wake evolution with rising tide}

5 As mentioned in section 2, turbine wake length $L$ is defined as the distance where velocity deficit $\boldsymbol{\delta}(\boldsymbol{x})$ drops down to $10 \%$. Ambient velocity $\boldsymbol{U}_{\boldsymbol{r e f}}(\boldsymbol{x})$ is the upwind velocity (Käsler et al., 2010) or the lateral velocity outside of the wake region (Smalikho et al., 2013). When the wind turbine operates susceptible to others, the ambient velocity is more turbulent and slightly smaller than that in free stream. In this case, the lateral velocity outside of turbine wakes should be taken as ambient velocity. While, $\boldsymbol{U}_{\text {wake }}(\boldsymbol{x})$ is the wake velocity along wake orientation. A case of retgrieved field is shown in Fig. 4, in

10 which the spatial resolution of wind speed (denoted by colous) is $15 \mathrm{~m}$ and the corresponding of wind direction (indicated by arrows) is $45 \mathrm{~m}$. The wake induced by wind turbine $\mathrm{T} 1$ appeared as cooler colours clearly in the downwind direction. Incremental cross sections are plotted as black rectangles and red squares in Fig. 4 to extract ambient and wake velocities shown in Fig. 5 as black crosses and red squares, respectively. And top 5\% velocities in each cross section were selected as ambient velocity $\boldsymbol{U}_{\boldsymbol{r e f}}(\boldsymbol{x})$ and denoted as black points. The ambient and wake velocities were then averaged by $0.5 \mathrm{D}$ axial

15 bins as black and red triangles. Consequently, the velocity deficit $\boldsymbol{\delta}(\boldsymbol{x})$ against the distance downwind was straightforward to be calculated from Eq.(1) as shown in Fig. 6. The velocity deficit did not apparently reduce when $\mathrm{x} \leq 6 \mathrm{D}$ due to the increasing altitude along the wake direction, from approximately $45 \mathrm{~m}$ to $80 \mathrm{~m}$, resulting in getting close to hub height (relatively higher velocity deficit in vertical direction). By the way, the base of wind turbine T1 located in the intertidal zone was lower than both two lidars, resulting in that the hub height of $\mathrm{T} 1$ is slightly lower than $80 \mathrm{~m}$. However when the downstream distance was beyond $6 \mathrm{D}$, the velocity deficit decreased sharply, partly due to keeping away from hub height. 
Atmos. Meas. Tech. Discuss., doi:10.5194/amt-2017-23, 2017

Manuscript under review for journal Atmos. Meas. Tech.

Discussion started: 31 March 2017

(c) Author(s) 2017. CC-BY 3.0 License.

(c) (i)

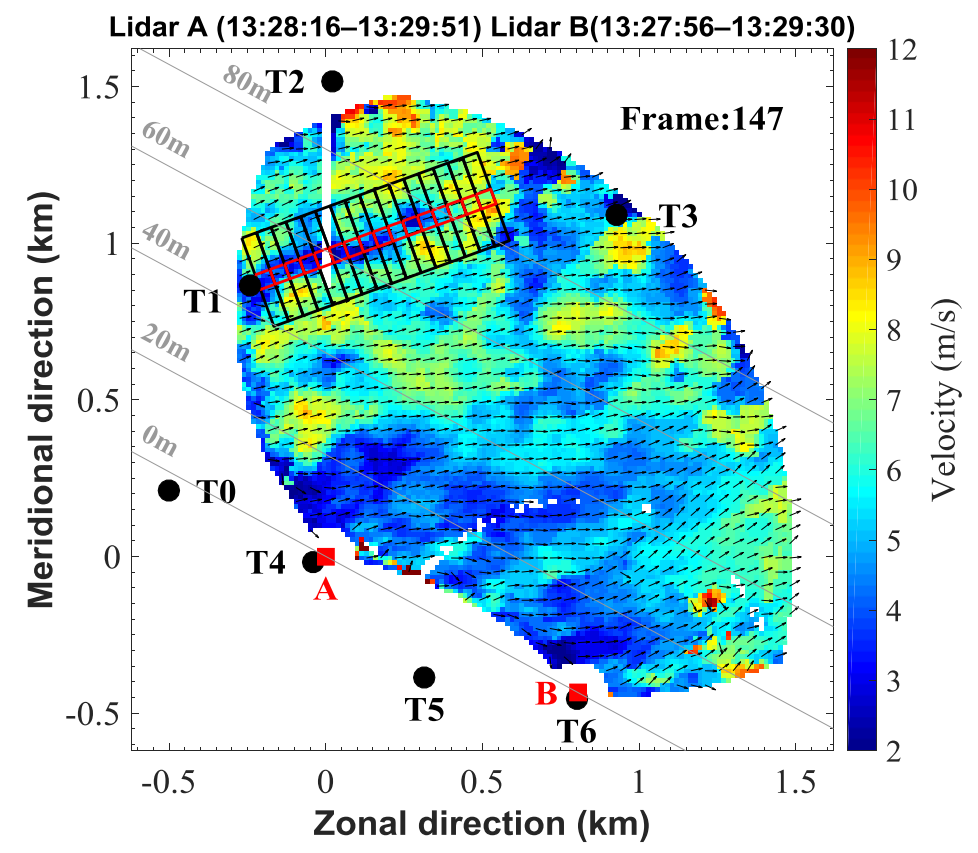

Figure 4: Retrieved vector wind field at intertidal wind farm in China from 1327 LT to 1330 LT on December 15, 2014. The spatial resolution of wind speed is $15 \mathrm{~m}$ and the corresponding of wind direction is $\mathbf{4 5 m}$. Red squares and black points indicate two lidars and wind turbine generators, respectively. The gray lines are contours of the titled measurement plane. Velocities in the incremental cross-sections (denoted by red squares and black rectangles) could be extracted to calculate ambient and wake velocities.

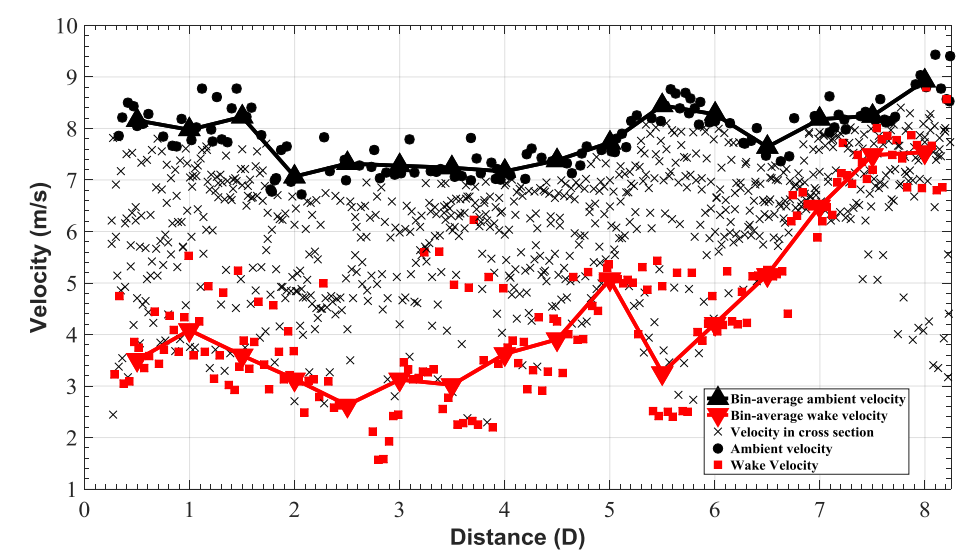

Figure 5: Wind velocities in the incremental cross-sections (as indicated by red squares and black rectangles) are plotted against the distance downwind as red squares, black crosses. The black points are top $5 \%$ of black crosses in each cross-section and used as ambient velocities. The red and black triangles are calculated by $0.5 \mathrm{D}$ rang bins. 
Atmos. Meas. Tech. Discuss., doi:10.5194/amt-2017-23, 2017

Manuscript under review for journal Atmos. Meas. Tech.

Discussion started: 31 March 2017

(c) Author(s) 2017. CC-BY 3.0 License.

(c) (i)
Atmospheric

Measurement

Techniques

Discussions

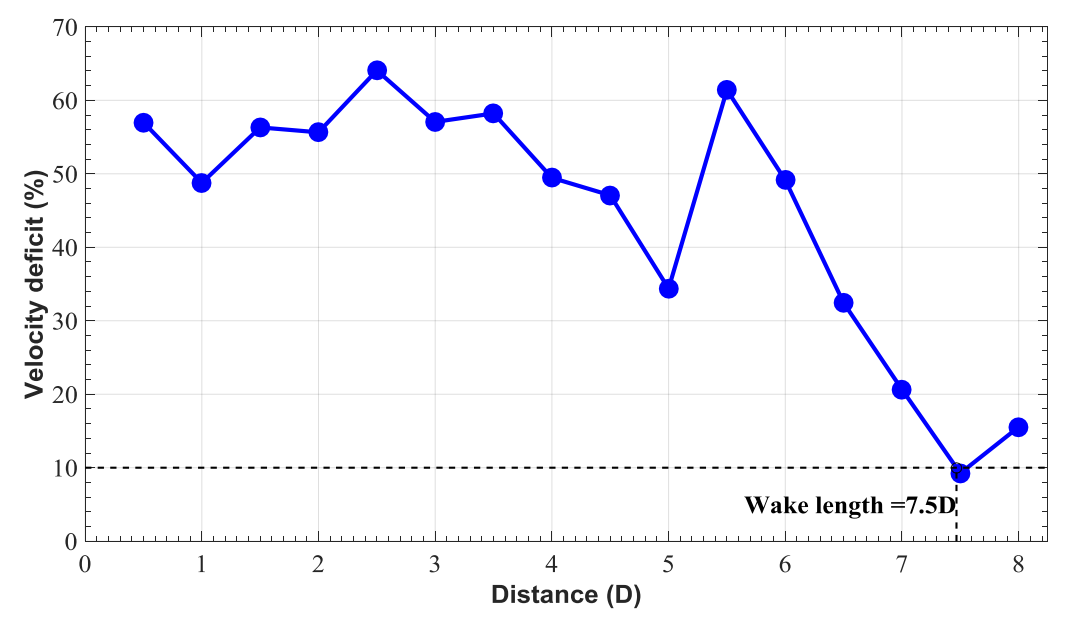

Figure 6: Variation of wake velocity deficit with downstream distance (in the form of rotor diameter D) is indicated by blue points and wake length $L$ is calculated as the distance where velocity deficit drops down to $10 \%$.

The maximum wind speed and mean wind direction in the altitude of $60 \mathrm{~m}, 70 \mathrm{~m}$ and $80 \mathrm{~m}$ were then averaged by $30 \mathrm{~min}$

temporal bins as ambient wind speeds and directions shown in Fig. 7(a) and (b) respectively. The turbulence intensity, $I_{u}=\sigma_{u} / U$, could be calculated as the dividing standard deviation of velocity $\sigma_{u}$ by the mean of velocity $U$ and shown in Fig. 7(c). The variation of wake length $L$ with rising tide could be obtained by applying the method described previously to the wind field results which have clearly visual feature as same as Fig. 3 with a total number of 26, and is shown in Fig. 7(d). Recall that tide rose from approximately 1204LT and reached the maximum level at about 1811LT. At 1525 LT, the intertidal zone was completely covered by tidewater exactly according to experimental records. The tide rising period ranging from $1230 \mathrm{LT}$ to $1700 \mathrm{LT}$ was divided into two stages. The wake of wind turbine T1 in this period located in the intertidal zone judging from that wind direction veered from southwest (about $220^{\circ}$ ) at $1200 \mathrm{LT}$ to west $\left(270^{\circ}\right)$ at $1413 \mathrm{LT}$ and to northwest $\left(295^{\circ}\right)$ at $1700 \mathrm{LT}$.

In stage 1 (from $1230 \mathrm{LT}$ to $1525 \mathrm{LT}$ ), the underlying surface transformed from mud to sea water and the mean wake length

15 was about 7D with southwesterly wind until 1410 LT. Subsequently, wake length increased to about $10 \mathrm{D}$ at $1415 \mathrm{LT}$ and 11.7 $\mathrm{D}$ at $1450 \mathrm{LT}$ with no obvious fluctuation of wind speed $\left(9.0 \mathrm{~ms}^{-1}-8.8 \mathrm{~ms}^{-1}\right)$ and turbulence intensity $(7 \%-10 \%)$ at $80 \mathrm{~m}$ height. Typical roughness of flattish ground and ocean surface is approximately $0.03 \mathrm{~m}$ and $<0.001 \mathrm{~m}$ (wind speed $<20 \mathrm{~ms}^{-}$ ${ }^{1}$ ), respectively (Emeis, 2012). Accordingly, this wake length increase was primarily caused by the influence of surface roughness transition.

20 In stage 2 (from $1525 \mathrm{LT}$ to $1638 \mathrm{LT}$ ), the hub height relative to the underlying sea surface decreased due to the rising tide with wind speed ranging from $8.4 \mathrm{~ms}^{-1}$ to $9.5 \mathrm{~ms}^{-1}$, wind direction veering from approximately $285^{\circ}$ to $290^{\circ}$ and turbulence intensity fluctuating around $10 \%$. The obviously declining to $7.8 \mathrm{D}$ and $8.4 \mathrm{D}$ appeared at $1542 \mathrm{LT}$ and $1546 \mathrm{LT}$ with wake orientation veering from $93^{\circ}$ to $115^{\circ}$, respectively, presumably due to that the yaw angle of the wind turbine could not be tuned immediately to be aligned with ambient wind direction. Despite all this, wake length increased obviously to $15.6 \mathrm{D}$ at 
Atmos. Meas. Tech. Discuss., doi:10.5194/amt-2017-23, 2017

Manuscript under review for journal Atmos. Meas. Tech.

Discussion started: 31 March 2017

(C) Author(s) 2017. CC-BY 3.0 License.

\section{Atmospheric \\ Measurement \\ Techniques \\ Discussions}

cc) (i)

1554 LT with wind speed, wind direction and turbulence intensity of $9 \mathrm{~ms}^{-1}, 285^{\circ}$ and approximately $10 \%$, respectively, at $80 \mathrm{~m}$ height. In this case, underlying surface roughness was not supposed to vary significantly because of no obviously wind speed fluctuating. Therefore, this wake growth was mainly attributed to the tide rising leading to decreased hub height or equivalently enhanced "ground effect", which weakened wake decay in far wake region. It should be pointed out that the the higher temperature of the sea surface (approximately $10^{\circ}$ ) than the air (less than $6^{\circ}$ ) may resulte in surface turbulence which subsequently reduced the wake length by stronger dissipating effect than in stable boundary layer. The unstable air flow possiblely leaded to the wake length reducing to $14.5 \mathrm{D}$ and $13.5 \mathrm{D}$ at $1614 \mathrm{LT}$ and $1616 \mathrm{LT}$, respectively. However, the wake lenth still increased to $18 \mathrm{D}$ at $1638 \mathrm{LT}$ due to rising sea level.

To sum up, wake length increased in tide rising period resulting from underlying surface roughness transition, rising sea level.
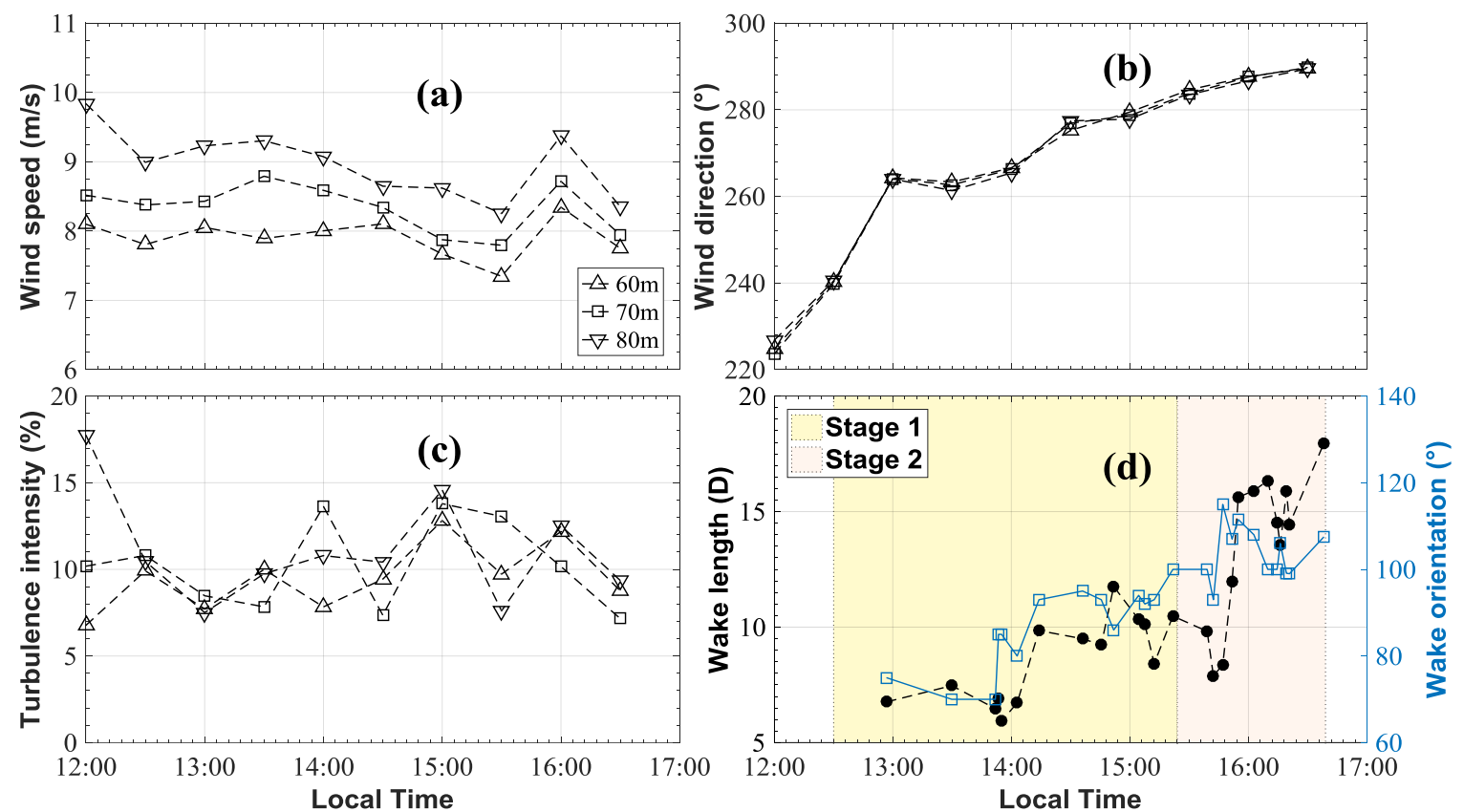

Figure 7: Variation of ambient wind speed (a), wind direction (b), turbulence intensity (c) and wake length and orientation (d) with rising tide from $1200 \mathrm{LT}$ to $1700 \mathrm{LT}$. The rising tide period is divided into three stages as shown by different shadows in (d). The wind speed (a), wind direction (b) and turbulence intensity (c) are given in the height of $60 \mathrm{~m}, 70 \mathrm{~m}$ and $80 \mathrm{~m}$.

\section{$15 \quad 3.3$ Wake meandering}

Wake meandering, defined as a random oscillation, is generated and driven when the turbulence length scales are larger than the wake width (España et al., 2011) based on the basic wake meandering model (Bingöl et al., 2010; Larsen et al., 2008). It can be used to evalute power production, wind turbine loading (Chamorro and Porté-Agel, 2010; Larsen et al., 2008). Significance of wake meandering research lies in its potential for application in optimization of wind farm topology and operation as well as in the optimization of wind turbines for wind farm applications (Larsen et al., 2008). It is shown that 
Atmos. Meas. Tech. Discuss., doi:10.5194/amt-2017-23, 2017

Manuscript under review for journal Atmos. Meas. Tech.

Discussion started: 31 March 2017

(c) Author(s) 2017. CC-BY 3.0 License.

(c) (i)

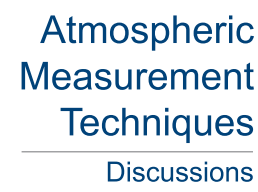

wake meandering is greater at higher ambient turbulence intensity conditions (Abkar and Porté-Agel, 2015; Bingöl et al., 2010; Chamorro and Porté-Agel, 2010) and lidar measuring technique could further investigate the fundamental assumption behind the present meandering theory (Larsen et al., 2008).

Since the cross-section wind profile has the distribution of single or double Gaussian shape, wake centre, and width could be

5 subsequently deduced by the least square fit method with single or double Gaussian curve described in section 2. As shown in Fig. 8, wind speed in cross-section as a function of relative distance to wake centre was fitted by the least square method with single and double Gaussian distribution denoted by red and black curves, respectively. While the wake centre was obtained from Eq.(1) and Eq.(2) by a preliminary fit process. The fit was performed iteratively in an attempt to estimate the upper and lower range of variables. However, only one fitted curve with minimum fitting RMSE (root-mean-square error)

10 was adopted to calculate wake centre and width. Then, wake centre line and wake length downwind behind the turbine could be derived by applying this method to the incremental wake sections. As shown in Fig. 9, wake centre and width are denoted by black lines and points, and the meandering effect could be seen clearly downwind of turbine T1 with approximately $16 \mathrm{D}$ wake length.

As shown in Fig. 10, wake width reduced from $2 \mathrm{D}$ at the distance of $x=0.5 \mathrm{D}$ to $1.4 \mathrm{D}$ at $x=5 \mathrm{D}$ with little variation of wake

15 centre height (about $45 \mathrm{~m}$ in Fig. 11), which was most likely relative to the fact that wake centre shifts upward in vertical location (Aitken et al., 2014; Papadopoulos et al., 1995). After 5D, wake meandering was obvious and the height of wake centre would rise due to the result observed in the tilted plane, which could be seen clearly in Fig. 10 that the height of wake centre in tilted plane rose at the distance of $x>5 \mathrm{D}$. Meanwhile, observed wake width grew to about 4.2 D at approximately 10.5D downwind of $\mathrm{T} 1$ arising from that wake expands larger with downwind distance (Aitken et al., 2014). However, wake

20 width fluctuated obviously ranging from $4.2 \mathrm{D}$ to $1.5 \mathrm{D}$ in far wake region as shown in Fig. 10. The main reasons were the turbulence diffusing effect resulting in less precise detection, inherent variability of the wake, as well as the meandering effect (Aitken et al., 2014). It should be pointed out that the observed wake width was unavoidably underestimated compared with the horizontal width across wake centre at hub height because the height of observed wake region (from about $45 \mathrm{~m}$ to $65 \mathrm{~m})$ was below hub height $(80 \mathrm{~m})$. 
Atmos. Meas. Tech. Discuss., doi:10.5194/amt-2017-23, 2017

Manuscript under review for journal Atmos. Meas. Tech.

Discussion started: 31 March 2017

(C) Author(s) 2017. CC-BY 3.0 License.

\section{Atmospheric \\ Measurement \\ Techniques \\ Discussions}

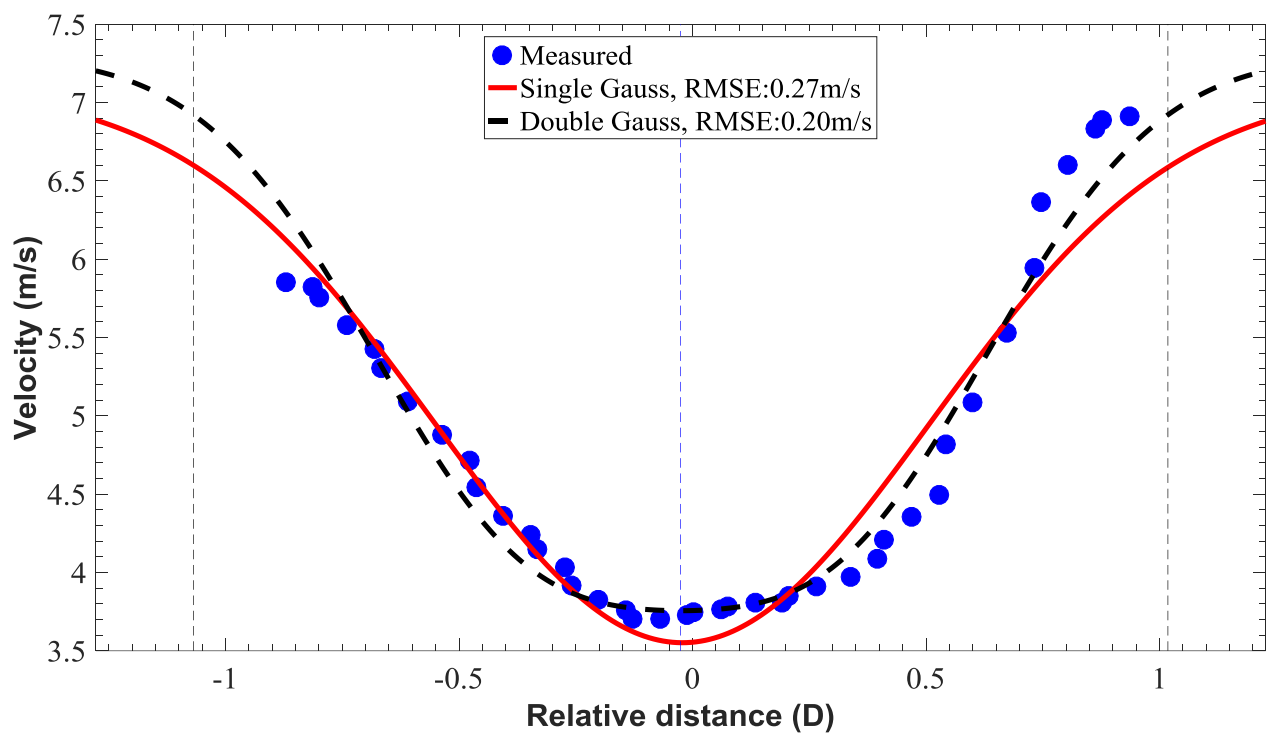

Figure 8: Variation of the wind speed (denoted by blue points)in a transect across wind turbine wake as a function of the distance from the center of the wake, are fitted by single Gaussian (red curve) and double Gaussian (black dash curve) curves, respectively.

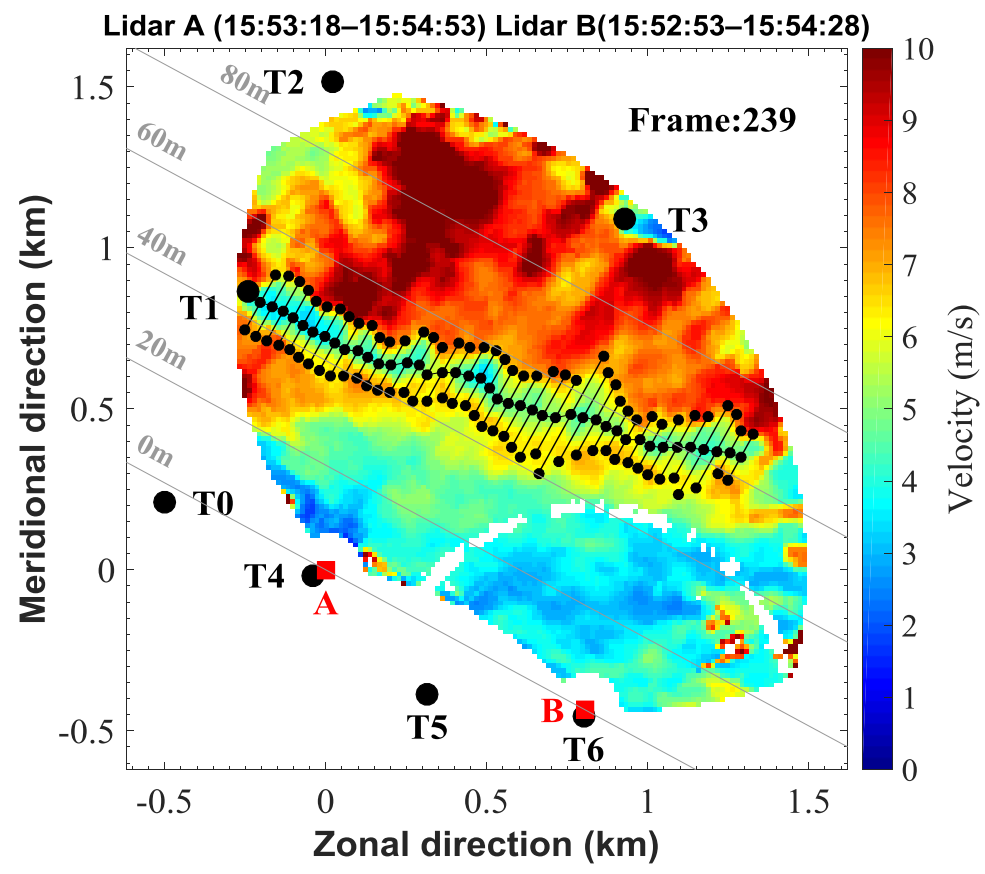

5 Figure 9: Retrieved wind speed (with spatial resolution of $15 \mathrm{~m}$ ) by two synchronously scanning lidars (denoted by red squares) around wind turbines (denoted by black points). Centre line and width (in the titled plane) of the wake behind wind generator $\mathrm{T} 1$ are denoted by black points and lines, respectively. 
Atmos. Meas. Tech. Discuss., doi:10.5194/amt-2017-23, 2017

Manuscript under review for journal Atmos. Meas. Tech.

Discussion started: 31 March 2017

(C) Author(s) 2017. CC-BY 3.0 License.

\section{(c) (i)}

\section{Atmospheric Measurement \\ Techniques \\ Discussions}

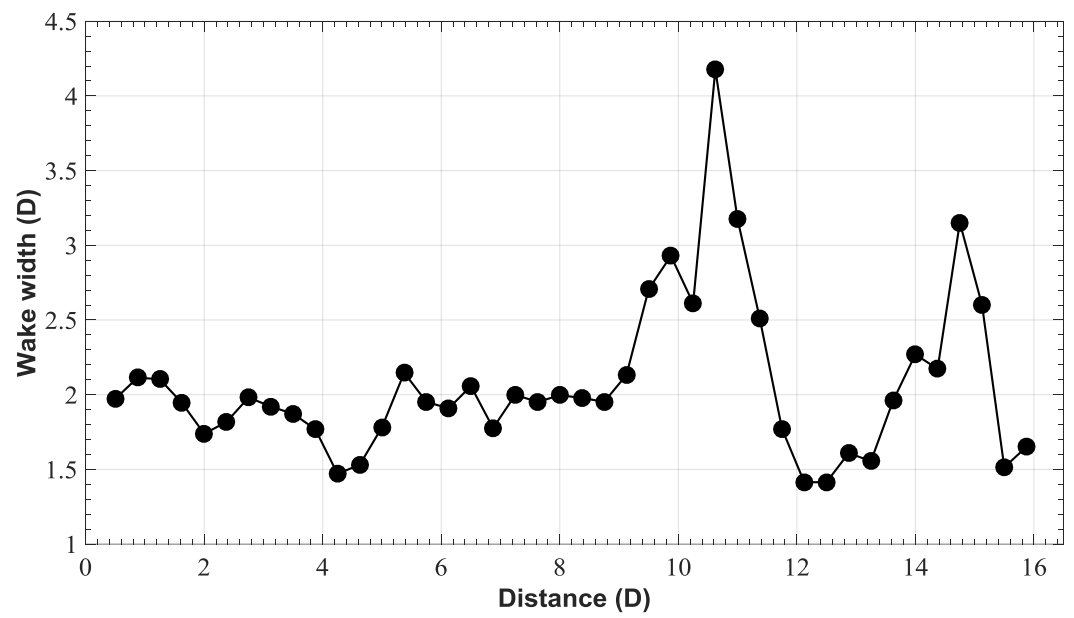

Figure 10: Variation of wake width in the titled plane with downstream distance from wind turbine generator T1

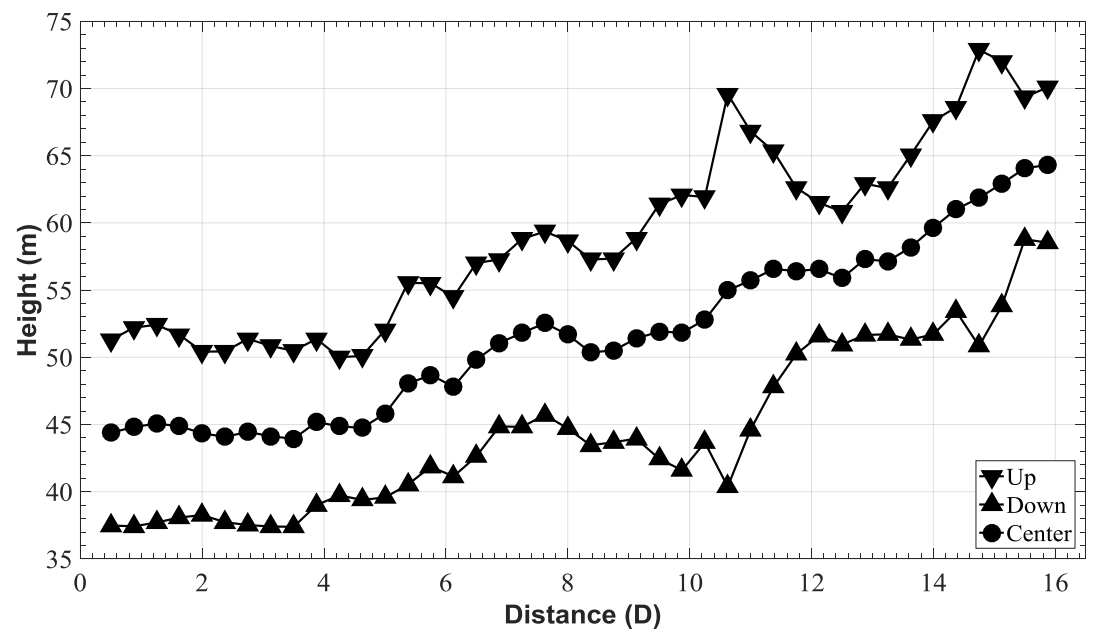

Figure 11: Height of wake boundary (up and down parts in tilted plane) and centreline observed in tilted plane.

5 Statistics of the wake centrelines is shown in Fig. 12 and the displacement to lateral distance against increasing wake axial distance is irregular with assumption of Gaussian frequency distribution in horizontal lateral direction $y$ (Högström et al., 1988):

$f=A \exp \left(-y^{2} / 2 \sigma_{c}^{2}\right)$,

while, $f$ has the normalizing requirement,

$10 \int_{-\infty}^{\infty} f(y) \mathrm{d} y=1$, 
Atmos. Meas. Tech. Discuss., doi:10.5194/amt-2017-23, 2017

Manuscript under review for journal Atmos. Meas. Tech.

Discussion started: 31 March 2017

(C) Author(s) 2017. CC-BY 3.0 License.

(c) (i)

\section{Atmospheric Measurement \\ Techniques \\ Discussions}

and $\sigma_{c}$ is the standard deviation of Gaussian frequency distribution with linear increase at longitudinal distance $x \leq 1 \mathrm{~km}$ downstream of the wind turbine:

$\sigma_{c}=k x$

where, $k$ is the slope value with 0.053 in (Högström et al., 1988). Subsequently, the standard deviation of wake centreline

5 displacement was calculated and presented in Fig. 13 as black squares. The linear relationship between longitudinal distance $x$ and $\sigma_{c}$ was calculated by linear fitting and indicated as blue line in Fig. 13 with slope value of 0.057 , which was slightly larger than 0.053 presumably due to stronger mesoscale wind fluctuations (Högström et al., 1988). However when longitudinal distance exceeded $10 \mathrm{D}$, the nonlinear relationship was obvious that $\sigma_{c}$ has the similarly exponential increase and expressed as red curve in Fig. 13. That would be the main reason why the wake lengths observed by in situ measurements were less than by other remote sensing instruments.

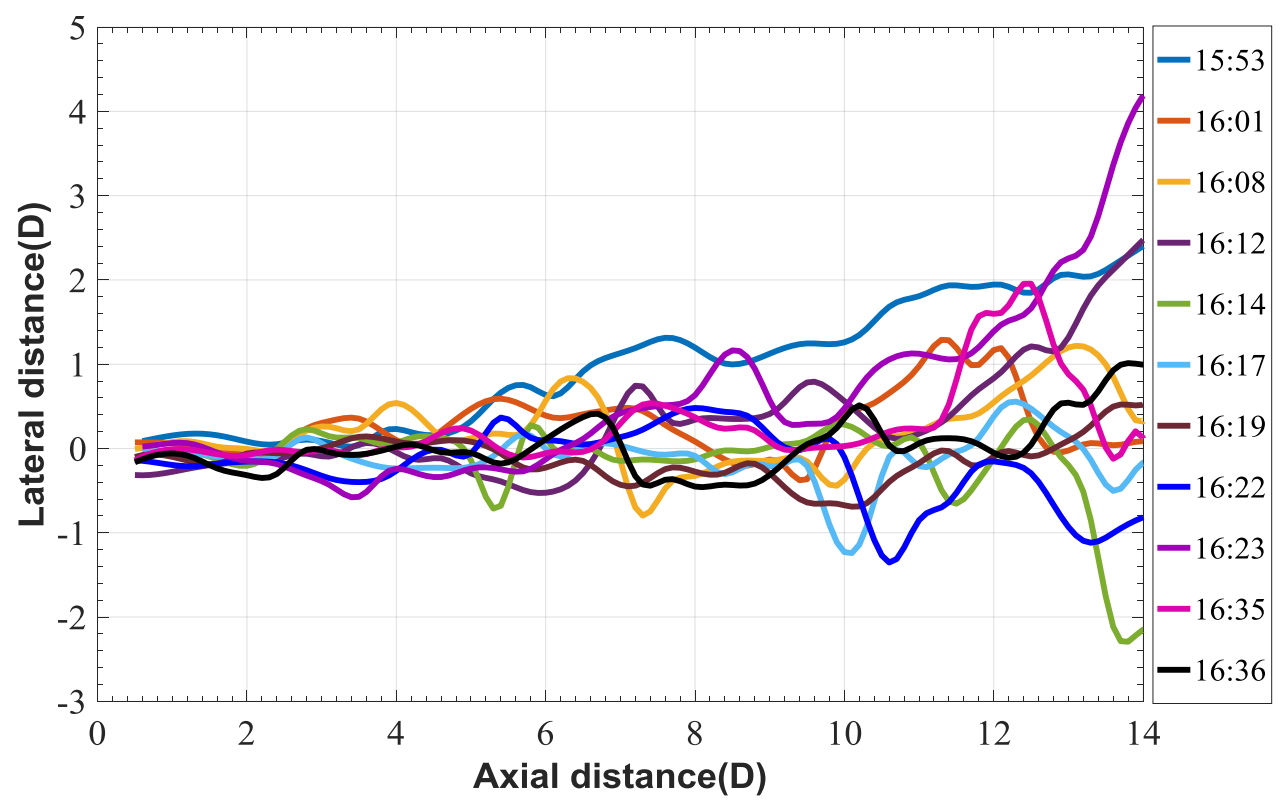

Figure 12: Statistics of wake centrelines displacement in lateral direction along wake axial distance 
Atmos. Meas. Tech. Discuss., doi:10.5194/amt-2017-23, 2017

Manuscript under review for journal Atmos. Meas. Tech.

Discussion started: 31 March 2017

(C) Author(s) 2017. CC-BY 3.0 License.

(c) (i)

\section{Atmospheric \\ Measurement \\ Techniques}

Discussions

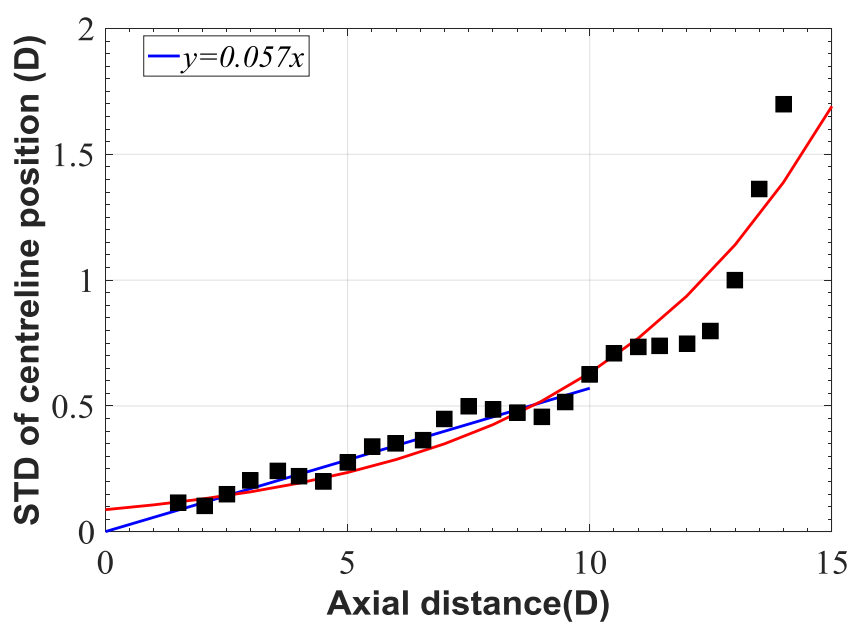

Figure 13: Standard deviation of centreline position as a function of axial distance in wake direction, the black squares are calculated from Figure 12, the blue line indicates the linear fit at the distance of $<1 \mathrm{~km}(10 \mathrm{D})$. The red curve represents exponential increase in the range of $<14 \mathrm{D}$.

\section{Conclusions}

In this study, we analyze wind turbine wake in the intertidal zone analysis based on the dual-Doppler method with a tilted plane scanning strategy. The conclusions drawn are in what follows.

The inclination angle of the tilted plane was tuned to $4^{\circ}$. In this case the altitude of the wind turbine $\mathrm{T} 1$ was approximately $45 \mathrm{~m}$ and below hub height of $80 \mathrm{~m}$, which was favorable to observe the far wake region to some extent. Moreover, this

10 method could be properly applied in the variable wind direction situation compared with traditional PPI or RHI scanning mode, in which the lidar-turbine line should be strictly aligned or roughly same with the turbine wake. Besides, wake analysis could be directly based on retrieved wind field, which is more convenient than LOS velocity or projection along wake direction utilizing only one lidar system. The pointing accuracy of the lidar beam scanner and the temporal difference of two LOS velocities at the same points should be further taken into account, which can be optimized by reducing angular

15 velocity and scanning a specific wake region, respectively. However, the ideal mounting location of lidar is on the nacelles, in which case wake structure in horizontal and vertical direction at hub height could be scanned by PPI with zero elevation angle and RHI mode transecting the wake centreline due to lidar yawing along with the wind turbine.

The wakes of onshore wind turbines with the crosswind distance of about $5 \mathrm{D}$ gradually merged together from separation statue in approximately 6 minutes. The wind direction in the retrieved wind field was approximately $205^{\circ}$, that was, the wind

20 blew from both lidars to the overlap region. Consequently, we observed both wide wakes induced by two wind turbines in the vicinity of two systems. In this case, a double wake pattern in the retrieved wind field was observed and subsequently both wakes swing to each other in lateral direction. Analysis of the transect across the wake at the distance of about $1 \mathrm{~km}$ downstream of both turbines showed a maximum velocity deficit of approximately $59 \%$ with separation statue and wakes 
Atmos. Meas. Tech. Discuss., doi:10.5194/amt-2017-23, 2017

Manuscript under review for journal Atmos. Meas. Tech.

Discussion started: 31 March 2017

(c) Author(s) 2017. CC-BY 3.0 License.

(c) (i)

Atmospheric

Measurement

Techniques

Discussions

recovering along with the merging process. This phenomenon could be observed within $1 \mathrm{D}$ downwind distance, different with the result studied by $\mathrm{Li}$ and Lehner based on X-band TerraSAR data, in which both wakes merge completely $70 \mathrm{D}$ away from the turbines. The difference could attribute to observation height difference (10m above sea level in their study), as well as the wind direction relative to the column of the turbines.

5 Wind turbine wake evolution with rising tide was elaborately analysed and directly towards two stages. In the first stage, observed wake length increased gradually from approximately $7 \mathrm{D}$ to $14 \mathrm{D}$ with underlying surface transition. This wake length increase primarily was attributed to the influence of surface roughness transition by ruling other factors out, such as no obvious fluctuation of wind speed $\left(9.0 \mathrm{~ms}^{-1}-8.8 \mathrm{~ms}^{-1}\right)$ and turbulence intensity $(7 \%-10 \%)$ at hub height. In the second stage, wake length increased to $15.6 \mathrm{D}$ attributed to the hub height decrease relative to underlying surface. In this period, that

10 wake length declined firstly with large wake orientation fluctuation of $22^{\circ}$ in 4 minutes was not taken into account because the yaw angle of wind turbine could not be properly aligned with wind direction. The analysis of wake evolution with rising tide showed the impact of underlying surface roughness and rising sea level on the wake. Further experiments are planned to quantify these factors based on long-term observations. Wake meandering case was also analysed based on the characteristic of the cross-section velocity distribution.

15 The previous method of velocity deficit calculation might be affected by the meandering especially in the far wake region as the selected wake regions deviate from the wake centreline. Nevertheless, as the wake propagated downstream and was mixed by small-scale ambient turbulence, it was difficult to distinguish the centreline of sufficiently dissipated wake. Moreover, the wake meandering introduced a new problem of whether the wake length was calculated by the wake centreline length or the length from wake centreline to the wind turbine. Besides, wake meandering is a random oscillation

20 as mentioned above, which seemed to have no relationship with rising tide. By considering all these, the severe meandering wakes were ruled out in the wake length calculation for simplification.

Both sides of the observed ambient velocities outside of the wake were different due to the tilted plane resulting in different heights, which would cause asymmetry double Gaussian curve and further bring large bias of wake centre and width. As a result, the length of the cross-section should be narrow enough. However to guarantee the fitting precision, more data points means longer cross-section. Accordingly, the adopted length of cross-section was a tradeoffs between both requirements.

In summary, wake behaviour could be properly observed based on the dual-lidar method for its feasibility in variety wind direction. But the more ideal mounting location of lidar is on the nacelles. Besides, further field experiments shall be performed to quantify the dependence of the wake behaviour (velocity deficit, wake length, wake boundary and wake centreline) on the atmospheric condition (wind speed, turbulence, surface roughness and atmospheric stability) combined

30 with turbine model, and ultimately improve the prediction of wind power harvesting. 
Atmos. Meas. Tech. Discuss., doi:10.5194/amt-2017-23, 2017

Manuscript under review for journal Atmos. Meas. Tech.

Discussion started: 31 March 2017

(c) Author(s) 2017. CC-BY 3.0 License.

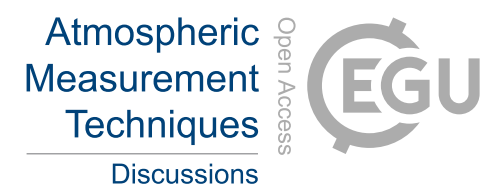

\section{Acknowledgement}

We thank our colleagues for their kind support during the field experiments and results discussion, including Quanfeng Zhuang, Guining Wang and Xiaoqing Yu from Ocean University of China (OUC) for the preparing and conducting the experiment; Yilin Qi and Jie Bai from Seaglet Environment Technology for preparing and operating the lidar in the cold and

5 windy wind farm. This work was partly supported by the National Natural Science Foundation of China (NSFC) under grant 41471309 and 41375016.

\section{References}

Abkar, M. and Porté-Agel, F.: Influence of atmospheric stability on wind-turbine wakes: A large-eddy simulation study, Physics of Fluids (1994-present), 27, 19, 2015.

10 Aitken, M. L., Banta, R. M., Pichugina, Y. L., and Lundquist, J. K.: Quantifying wind turbine wake characteristics from scanning remote sensor data, Journal of Atmospheric and Oceanic Technology, 31, 765-787, 2014.

Aitken, M. L. and Lundquist, J. K.: Utility-scale wind turbine wake characterization using nacelle-based long-range scanning lidar, Journal of Atmospheric and Oceanic Technology, 31, 1529-1539, 2014.

Armijo, L.: A theory for the determination of wind and precipitation velocities with Doppler radars, Journal of the Atmospheric Sciences,

$1526,570-573,1969$.

Anderson, J. W. and Clayton, G. M.: Lissajous-like scan pattern for a gimballed LIDAR, 2014, 1171-1176.

Baker, R. W. and Walker, S. N.: Wake measurements behind a large horizontal axis wind turbine generator, Solar Energy, 33, 5-12, 1984.

Barthelmie, R., Folkerts, L., Ormel, F., Sanderhoff, P., Eecen, P., Stobbe, O., and Nielsen, N.: Offshore wind turbine wakes measured by SODAR, Journal of Atmospheric and Oceanic Technology, 20, 466-477, 2003.

20 Barthelmie, R. J. and Jensen, L.: Evaluation of wind farm efficiency and wind turbine wakes at the Nysted offshore wind farm, Wind Energy, 13, 573-586, 2010.

Bingöl, F., Mann, J., and Larsen, G. C.: Light detection and ranging measurements of wake dynamics part I: one - dimensional scanning, Wind energy, 13, 51-61, 2010.

Chamorro, L. P. and Porté-Agel, F.: Effects of thermal stability and incoming boundary-layer flow characteristics on wind-turbine wakes:

25 a wind-tunnel study, Boundary-layer meteorology, 136, 515-533, 2010.

Chowdhury, S., Zhang, J., Messac, A., and Castillo, L.: Unrestricted wind farm layout optimization (UWFLO): Investigating key factors influencing the maximum power generation, Renewable Energy, 38, 16-30, 2012.

Elliott, D. and Barnard, J.: Observations of wind turbine wakes and surface roughness effects on wind flow variability, Solar Energy, 45, 265-283, 1990.

30 Emeis, S.: Wind energy meteorology: atmospheric physics for wind power generation, Springer Science \& Business Media, 2012.

España, G., Aubrun, S., Loyer, S., and Devinant, P.: Spatial study of the wake meandering using modelled wind turbines in a wind tunnel, Wind Energy, 14, 923-937, 2011.

Fuertes, F. C., Iungo, G. V., and Porté-Agel, F.: 3D Turbulence Measurements Using Three Synchronous Wind Lidars: Validation against Sonic Anemometry, Journal of Atmospheric and Oceanic Technology, 31, 1549-1556, 2014.

35 Hansen, K. S., Barthelmie, R. J., Jensen, L. E., and Sommer, A.: The impact of turbulence intensity and atmospheric stability on power deficits due to wind turbine wakes at Horns Rev wind farm, Wind Energy, 15, 183-196, 2012.

Helmis, C., Papadopoulos, K., Asimakopoulos, D., Papageorgas, P., and Soilemes, A.: An experimental study of the near-wake structure of a wind turbine operating over complex terrain, Solar Energy, 54, 413-428, 1995.

Hirth, B. D. and Schroeder, J. L.: Documenting wind speed and power deficits behind a utility-scale wind turbine, Journal of Applied

40 Meteorology and Climatology, 52, 39-46, 2013.

Hirth, B. D., Schroeder, J. L., Gunter, W. S., and Guynes, J. G.: Coupling Doppler radar - derived wind maps with operational turbine data to document wind farm complex flows, Wind Energy, 18, 529-540, 2015.

Hirth, B. D., Schroeder, J. L., Gunter, W. S., and Guynes, J. G.: Measuring a utility-scale turbine wake using the TTUKa mobile research radars, Journal of Atmospheric and Oceanic Technology, 29, 765-771, 2012.

45 Högström, U., Asimakopoulos, D., Kambezidis, H., Helmis, C., and Smedman, A.: A field study of the wake behind a 2 MW wind turbine, Atmospheric Environment (1967), 22, 803-820, 1988.

Iungo, G. V.: Experimental characterization of wind turbine wakes: Wind tunnel tests and wind LiDAR measurements, Journal of Wind Engineering and Industrial Aerodynamics, 149, 35-39, 2016. 
Atmos. Meas. Tech. Discuss., doi:10.5194/amt-2017-23, 2017

Manuscript under review for journal Atmos. Meas. Tech.

Discussion started: 31 March 2017

(c) Author(s) 2017. CC-BY 3.0 License.

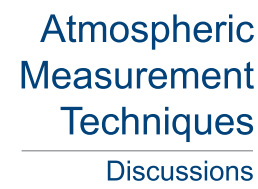

\section{(c) (i)}

Iungo, G. V., Wu, Y.-T., and Porté-Agel, F.: Field measurements of wind turbine wakes with lidars, Journal of Atmospheric and Oceanic Technology, 30, 274-287, 2013.

Kambezidis, H., Asimakopoulos, D., and Helmis, C.: Wake measurements behind a horizontal-axis $50 \mathrm{~kW}$ wind turbine, Solar \& wind technology, 7, 177-184, 1990.

5 Käsler, Y., Rahm, S., Simmet, R., and Kühn, M.: Wake measurements of a multi-MW wind turbine with coherent long-range pulsed Doppler wind lidar, Journal of Atmospheric and Oceanic Technology, 27, 1529-1532, 2010.

Kopp, F., Rahm, S., and Smalikho, I.: Characterization of aircraft wake vortices by 2-mu m pulsed Doppler lidar, Journal of Atmospheric and Oceanic Technology, 21, 194-206, 2004.

Larsen, G. C., Madsen Aagaard, H., Bingöl, F., Mann, J., Ott, S., Sørensen, J. N., Okulov, V., Troldborg, N., Nielsen, N. M., and Thomsen,

10 K.: Dynamic wake meandering modeling, Risø National Laboratory8755036023, 2007.

Larsen, G. C., Madsen, H. A., Thomsen, K., and Larsen, T. J.: Wake meandering: a pragmatic approach, Wind energy, 11, 377-395, 2008.

$\mathrm{Li}, \mathrm{X}$. and Lehner, S.: Observation of TerraSAR-X for studies on offshore wind turbine wake in near and far fields, IEEE Journal of Selected Topics in Applied Earth Observations and Remote Sensing, 6, 1757-1768, 2013.

Mann, J., Cariou, J. P., Courtney, M. S., Parmentier, R., Mikkelsen, T., Wagner, R., Lindelow, P., Sjoholm, M., and Enevoldsen, K.:

15 Comparison of 3D turbulence measurements using three staring wind lidars and a sonic anemometer, Meteorologische Zeitschrift, 18, 135140, 2009.

Papadopoulos, K., Helmis, C., Soilemes, A., Papageorgas, P., and Asimakopoulos, D.: Study of the turbulent characteristics of the nearwake field of a medium-sized wind turbine operating in high wind conditions, Solar Energy, 55, 61-72, 1995.

Porté-Agel, F., Wu, Y.-T., Lu, H., and Conzemius, R. J.: Large-eddy simulation of atmospheric boundary layer flow through wind turbines

20 and wind farms, Journal of Wind Engineering and Industrial Aerodynamics, 99, 154-168, 2011.

Ray, P. S., Wagner, K., Johnson, K., Stephens, J., Bumgarner, W., and Mueller, E.: Triple-Doppler observations of a convective storm, Journal of Applied Meteorology, 17, 1201-1212, 1978.

Rhodes, M. E. and Lundquist, J. K.: The effect of wind-turbine wakes on summertime US Midwest atmospheric wind profiles as observed with ground-based doppler lidar, Boundary-Layer Meteorology, 149, 85-103, 2013.

25 Rothermel, J., Kessinger, C., and Davis, D. L.: Dual-Doppler lidar measurement of winds in the JAWS experiment, Journal of Atmospheric and Oceanic Technology, 2, 138-147, 1985.

Smalikho, I., Banakh, V., Pichugina, Y., Brewer, W., Banta, R., Lundquist, J., and Kelley, N.: Lidar investigation of atmosphere effect on a wind turbine wake, Journal of Atmospheric and Oceanic Technology, 30, 2554-2570, 2013.

Smalikho, I., Kopp, F., and Rahm, S.: Measurement of atmospheric turbulence by 2-mu m Doppler lidar, Journal of Atmospheric and

30 Oceanic Technology, 22, 1733-1747, 2005.

Smedman, A.-S.: Air Flow Behind Wind Turbines, Journal of Wind Engineering and Industrial Aerodynamics, 80, 169-189, 1998.

Trujillo, J. J., Bingöl, F., Larsen, G. C., Mann, J., and Kühn, M.: Light detection and ranging measurements of wake dynamics. Part II: two - dimensional scanning, Wind Energy, 14, 61-75, 2011.

Vermeer, L., Sørensen, J. N., and Crespo, A.: Wind turbine wake aerodynamics, Progress in aerospace sciences, 39, 467-510, 2003.

35 Wu, S., Liu, B., Liu, J., Zhai, X., Feng, C., Wang, G., Zhang, H., Yin, J., Wang, X., Li, R., and Gallacher, D.: Wind turbine wake visualization and characteristics analysis by Doppler lidar, Opt. Express, 24, 19, 2016.

Wu, S., Yin, J., Liu, B., Liu, J., Li, R., Wang, X., Feng, C., Zhuang, Q., and Zhang, K.: Characterization of turbulent wake of wind turbine by coherent Doppler lidar, 2014, 92620H-92620H-92610.

Wu, Y.-T. and Porté-Agel, F.: Atmospheric turbulence effects on wind-turbine wakes: An LES study, energies, 5, 5340-5362, 2012. 